\title{
Hydatid Cysts: Three Different Stages on the Same Image
}

\author{
Fatih Ermis ${ }^{1}$, Memduh Dursun ${ }^{2}$, Filiz Akyüz ${ }^{1}$, Barıs Bakır ${ }^{2}$ and Koray Güven ${ }^{2}$
}

Key words: echinococcus, image, stage

(DOI: 10.2169/internalmedicine.46.0453)

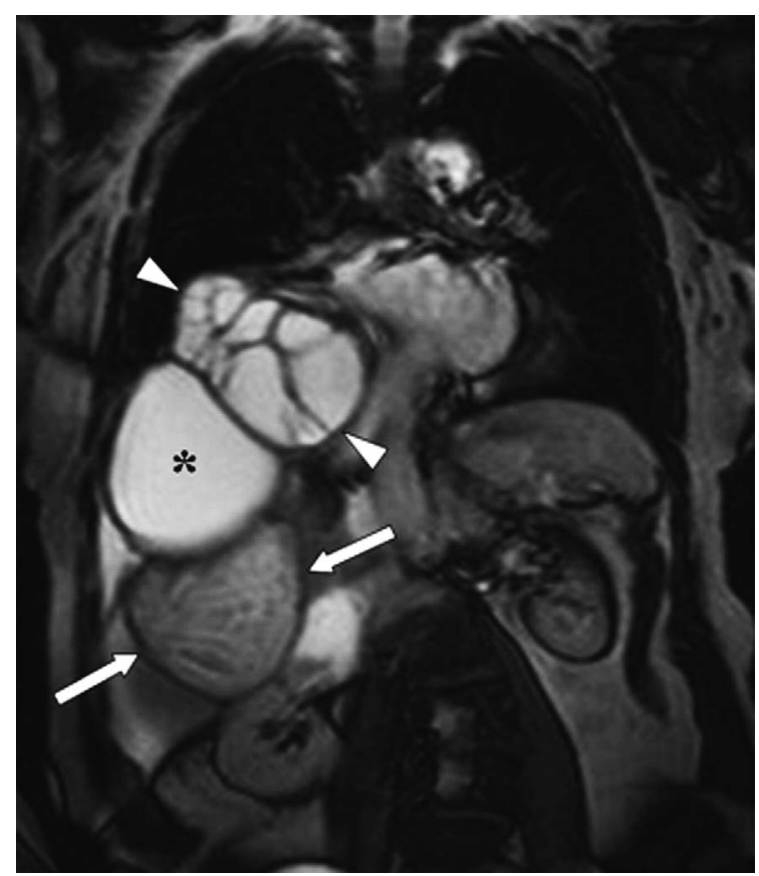

Picture 1. Coronal MR image showed that three lesions had different imaging features. The most superior lesion had multiple small cysts divided by septae, termed "daughter cysts" (arrowheads). The middle lesion was purely cystic with no septation (asterisk). The inferior most lesion (arrows) had multiple curvilinear hypointense signals indicating a germinative membrane.
An 82-year-old woman had a six-month history of right upper quadrant pain and palpable mass. On physical examination hepatomegaly and a palpable firm mass in the right upper quadrant was detected. Ultrasonography revealed three cystic lesions in the liver. On routine laboratory examination there was no significant abnormality, but serological tests for hydatid disease were positive. The patient was referred to our clinic for magnetic resonance (MR) imaging to evaluate the liver masses. Coronal MR image revealed that the three lesions had different imaging features (Picture 1). The most superior lesion had multiple small cysts divided by septae which are called "daughter cysts" (arrowheads). The middle lesion was purely cystic with no septation (asterisk). The inferior most lesion (arrows) had multiple curvilinear hypointense signals indicating a germinative membrane.

Echinococcus granulosus (EG) can affect any organ in the body; it is most commonly reported in the liver (up to $77 \%$ ). Diagnosis is often incidental and can be made with serological tests and imaging (1). Hydatid disease is often manifested by a slow growing cystic mass. Cysts may be single or multiple, uni- or multiloculated, and thin- or thick walled. More specific signs include the presence of daughter cysts, and membrane detachment; however, hydatid cysts may be seen from a purely cystic mass to a solid lesion (2).

Different phases of EG in the same patient is unusual. Here, we presented a rare clinical picture of a hydatid cyst in three different stages on the same coronal MR image.

\section{References}

1. Kıresi DA, Karabacakoglu K, Odev K, Karakose S. Uncommon locations of hydatid cysts. Acta Radiol 44: 622-636, 2003.
2. Engin G, Acunas B, Rozanes I, Acunas G. Hydatid disease with unusual localization. Eur Radiol 10: 1904-1912, 2000.

(C) 2007 The Japanese Society of Internal Medicine

http://www.naika.or.jp/imindex.html

\footnotetext{
${ }^{1}$ Department of Gastroenterohepatology, Istanbul University, Istanbul Faculty of Medicine, Istanbul and ${ }^{2}$ Department of Radiology, Istanbul University, Istanbul Faculty of Medicine, Istanbul, Turkey

Received for publication July 15, 2007; Accepted for publication July 19, 2007

Correspondence to Dr. Fatih Ermis, fatihermis2@hotmail.com
} 